Cristina Tartás y Rafael Guridi

\section{Los gasómetros del Zollverein Historia de una recuperación singular}

Palabras clave: gasómetro, gasholder, Zollverein, arquitectura industrial, patrimonio industrial, recuperación.

Por su rotundidad formal y gran volumen, los mal llamados gasómetros (no son medidores sino depósitos de gas) han devenido fácilmente en iconos o hitos asociados a la memoria del lugar defendidos por asociaciones ciudadanas y particulares. Tras una breve introducción analizando la situación actual y sus problemas de mantenimiento y pervivencia, en este trabajo se realiza un recorrido por su evolución y desarrollo histórico. Ello lleva a plantear la cuestión de la estrategias de conservación, considerándose imprescindible el estudio caso a caso, atendiendo a su estado, situación y relación con las comunidades de su entorno. Como ejemplo, el área de Zollverein en la cuenca del Ruhr ofrece un interesante conjunto de elementos sobrevivientes y recuperados que muestran diversas soluciones llevadas a la práctica.

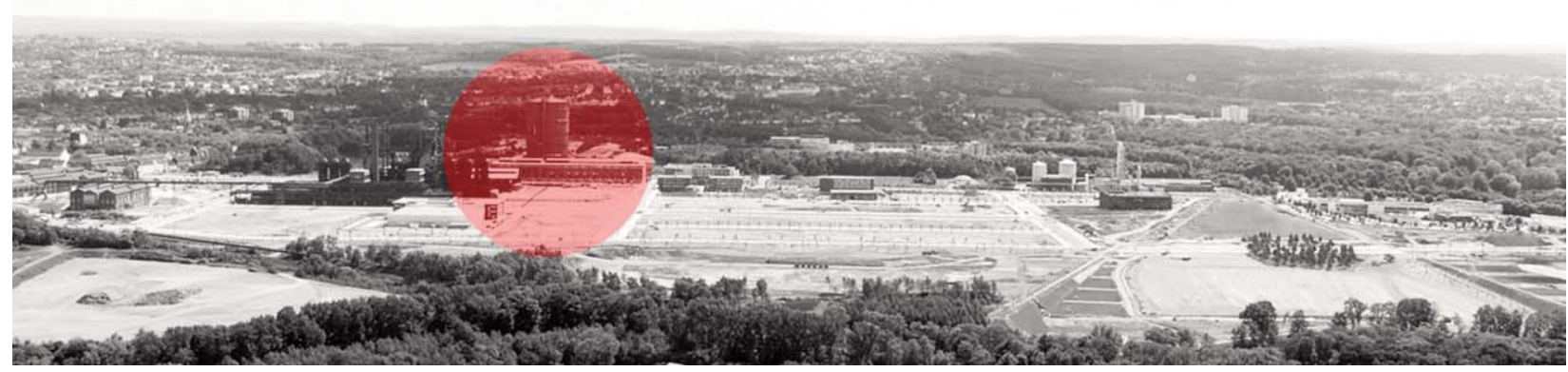

Vista de la fábrica Phoenix West (Altos Hornos) de Dortmund (fuente: www.industriedenkmal.de)

Cristina Tartás Ruiz, doctora arquitecta. $\mathrm{Ha}$ impartido clases en la ETS Arquitectura de la UPM, en el

Departamento de Arquitectura de la UAH y en la Escuela de Arquitectura de la Universidad Sek de Segovia (departamentos de Ideación y Proyectos).

Rafael Guridi García, doctor arquitecto. Es profesor de la ETS Arquitectura de la UPM desde el año 1998 hasta la actualidad en el Departamento de Proyectos.

Socios fundadores del estudio de arquitectura guriditartás arquitectos desde 1989.
Los -mal llamados- gasómetros (no son medidores, sino depósitos de gas) comparten con muchos otros elementos del Patrimonio Industrial amenazado ciertas características comunes, como su obsolescencia ante nuevos sistemas de producción y distribución y su emplazamiento en antiguas áreas industriales, originalmente situadas en la periferia y hoy desbordadas ante el desarrollo de nuevos emplazamientos urbanos valiosos, y por tanto sometidos a una enorme presión especuladora.

Sin embargo, presentan diferencias notables con otros elementos del tejido industrial que convierten su caso en singular debido a su gran volumen, su relativamente reducida escala urbana y su menor ocupación en planta frente a, por ejemplo, una gran fábrica o infraestructura; o también por su carácter puntual, más fácilmente integrable en nuevos desarrollos urbanos. Si a esto se une su rotundidad formal y la magnitud vertical que refuerzan su visibilidad, los gasómetros han devenido fácilmente en iconos o landmarks de un territorio, asociados a la memoria del lugar y defendidos por asociaciones ciudadanas y particulares como parte constitutiva de su memoria.

El problema de su recuperación no obstante presenta diversas disyuntivas, osci- lando entre dos polos opuestos de su comprensión como objeto: como elemento ornamental descontextualizado en un espacio libre, o como elemento funcional que conserve y dignifique su origen y usos iniciales. Entre estos últimos destacan los de la antigua cuenca industrial del Ruhr, autodenominada Zollverein en la actualidad, ${ }^{1}$ tanto por su relación espacial y temática con el paisaje y con la industria y las minas de carbón, como porque han conseguido una integración completa en la vida actual de las ciudades de esta región.

De su origen y tipología, de su evolución, transformación y recuperación, y de las razones de su supervivencia, se ocupa el presente artículo.

\section{Introducción: definición}

Los gasómetros eran los depósitos del gas que las fábricas de carbón producían como fuente de energía. Estaban vinculados a la producción del llamado "gas ciudad" utilizado en la industria, el alumbrado y el consumo doméstico; es decir, a la utilización del carbón como materia prima. Su relación con la tecnología del carbón fue tan estrecha que -quizá junto al humo de las fábricas- han sido la verdadera imagen de la Revolución Industrial, simbolo y paradigma de una época. 


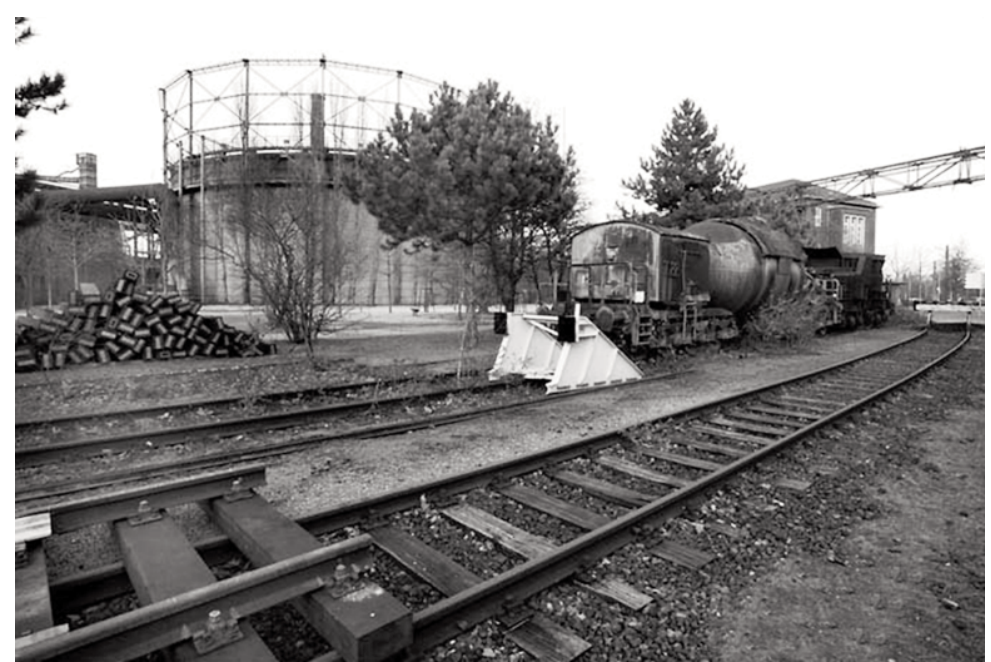

Gasómetro de Duisburg (1920), Alemania (fuente: (C) Oliver Frühschütz)

Gasómetro de Oberhausen (1929), Alemania fuente. (C) Thomas Machoczeck) superficie- y de funcionamiento muy simple: el gas se almacenaba a temperatura y presión ambientales, aumentando y disminuyendo su volumen según la producción y la demanda. O lo que es lo mismo: la forma final del contenedor no era fija, crecía o disminuía según las necesidades (y esto sucedía en todos los tipos, tanto en los gasómetros telescópicos, como en los secos o de pistón).

Decía Le Corbusier: "Existe una multitud de obras de espíritu nuevo que se encuentran, especialmente, en la producción industrial" (1923). Se refería a los paquebotes, los aviones o los silos (bastante parecidos en forma y tipología a los gasómetros). Aunque sin mencionarlos, se puede ver que esta cita encaja perfectamente por contexto con estos depósitos.

La segunda clave es la geometría. Parten de forma puras: cilindros rematados por casquetes esféricos, una forma elemental cuyo perfil se reconoce al instante, y que produce "esa satisfacción del espíritu": equilibrio, perfección, rotundidad, propia de la abstracción moderna (Le Corbusier 1926). Una geometría que nos conduce hacia su siguiente característica: el impacto visual.

La gran escala de estos depósitos debía contener el volumen de gas necesario a los requerimientos de una demanda próxima (industria y hogares). Durante el día la producción del gas llenaba el depósito, mientras que por la noche, por la iluminación y el consumo, se iba vaciando. De este fenómeno -expansión-contracción del

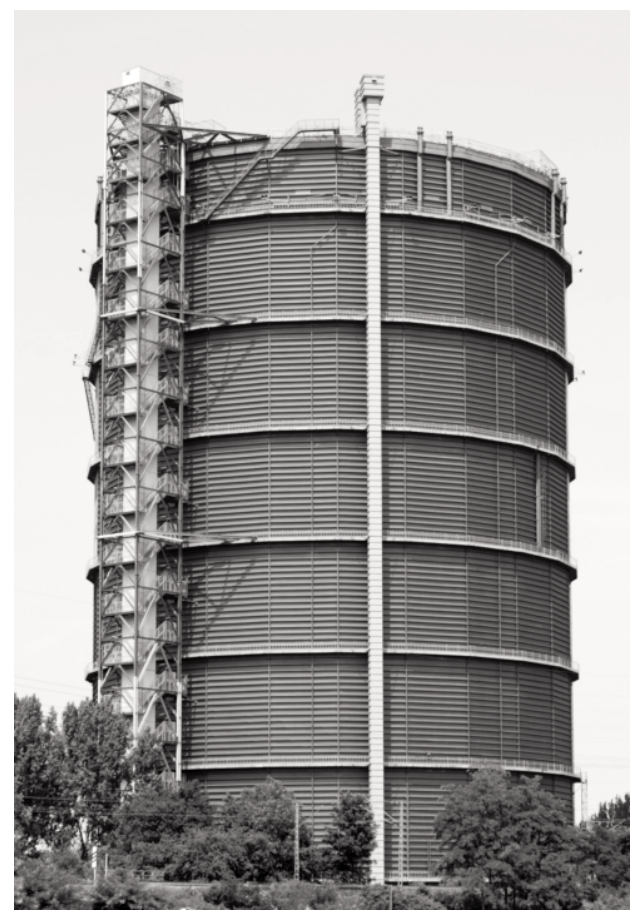


Esquemas de Gasómetro de agua (telescópico) y seco (de Wiggins) (fuente: $w w w)$ volumen del gas- nace una de sus cualidades más pregnantes: el cambio de forma vinculado al movimiento. Los gasómetros telescópicos son el ejemplo más claro: crecían durante el día con la producción de la fábrica y disminuían durante la noche, por el consumo doméstico. Esta condición o ritmo los asimilaba a un organismo vivo como la respiración o el pulso. En los testimonios de muchos de sus defensores actuales, el enigma sobre sus cambios de forma, es uno de sus recuerdos más intensos. ${ }^{5}$

Derivado del impacto visual de los gasómetros -y lo más importante para este caso- es su significado cultural y social. Su imponente presencia, el movimiento del depósito en los tipos telescópicos (aparición/ desaparición del volumen), junto al ruido aparejado a toda esta actividad recordemos que "gas" es una palabra parecida en casi todas las lenguas, porque proviene de la onomatopeya del sonido que produce este fluido al dispersarse- los convirtieron, probablemente desde el principio, en piezas icónicas, símbolos capaces de determinar un entorno y cualificar un paisaje, e hitos de fuerte impacto espacial, próximo y lejano. Y es que los gasómetros clásicos, ${ }^{6}$-frente a otras muchas instalaciones industriales apreciadas solo en ciertos sectores restringidos- han sido y son tremendamente populares. ${ }^{7}$

Esta característica, es decir el aprecio social del que casi siempre han gozado, ha sido y es la clave de su supervivencia y reutilización. Los gasómetros han conseguido resistir el desmantelamiento de la industria a la que se vinculaban, por ser un elemento en torno al cual la movilización de comunidades o sectores sociales, ha sido un éxito de la llamada "participa-

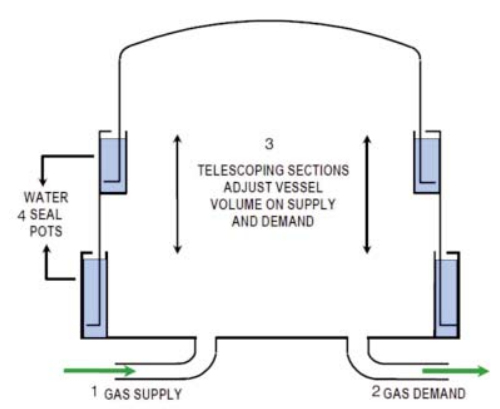

GASÓMEIRO TEIESCÓPICO

1. SUMNISTRO DE GAS 2 DEMANDA DE GAS

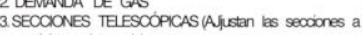
suministoy yemanda)
4.VASO DE SEUADO DEAGUA

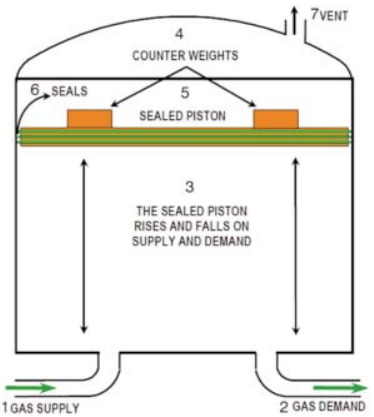

GASÓMEIRO DE PISTÓN 1.SUMNISTRO DE GAS
2 DEMANDA DE GAS demanca) 4. CONIPAPESOS
5.PSTÓNSELIADO SSE $A D O$ 7.VENTILACÓN 3. DEPOSTO (E pitión seledos s be y baja seginsumristroy ción ciudadana". Son uno de los pocos casos en los que un elemento industrial es aceptado como patrimonio comunitario, como parte esencial de la memoria colectiva.

Sus detractores dicen que los gasómetros son instalaciones industriales cuyo impacto visual -como hemos señalado- es considerable. La obsolescencia de estos depósitos y un mal estado de conservación produce una degradación del entorno en el que se encuentran. Además ocupan zonas industriales que si bien eran periféricas hasta mediados del siglo XX, hoy han sido absorbidas por el desarrollo de las ciudades y reconvertidas en áreas centrales, y por tanto muy codiciadas para los nuevos desarrollos. El mayor enemigo de estas instalaciones se encuentra hoy en la presión inmobiliaria.

Por otro lado, no hay que olvidar otro factor: la contaminación del suelo normalmente producida por la parte enterrada de estos depósitos y cuyo espesor mínimo oscilaba entre los cinco y quince metros. El antiguo gas ciudad era además especialmente tóxico. Por eso la reutilización de estos terrenos conlleva proyectos de recuperación y limpieza de costo elevado. Esta es la razón por la que las compañías propietarias de estos contenedores, se quejan del precio que tanto su mantenimiento como su desmantelamiento conllevan, argumentando -no sin razón- que recuperarlo no debería ser una tarea solo a su cuenta. 8

Situado entre estos intereses contrapuestos, el debate sobre la recuperación de los gasómetros es actualmente un tema abierto y controvertido.

\section{Historia, evolución y desarrollo}

El nombre de "gasómetro", el más utilizado en todas las lenguas, es sin embargo inexacto. El término data de 1815 y se debe -al parecer- a Samuel Clegg, discipulo de William Murdoch, inventor del sistema de iluminación por gas. Este término está, a su vez, tomado del aparato que Antoine de Lavoisier inventó para almacenar y medir gases en 1789 y que incorporaba una escala de medición. ${ }^{9} \mathrm{El}$ nombre se mantuvo, pero el gasómetro no mide el gas sino que simplemente lo contiene, controlando la presión y la temperatura.

En la actualidad tanto en inglés (Gashol der) como en alemán (Gasbehälter), el término empleado es contenedor de gas, porque en estos países es donde más se ha desarrollado su tecnología, más se ha 


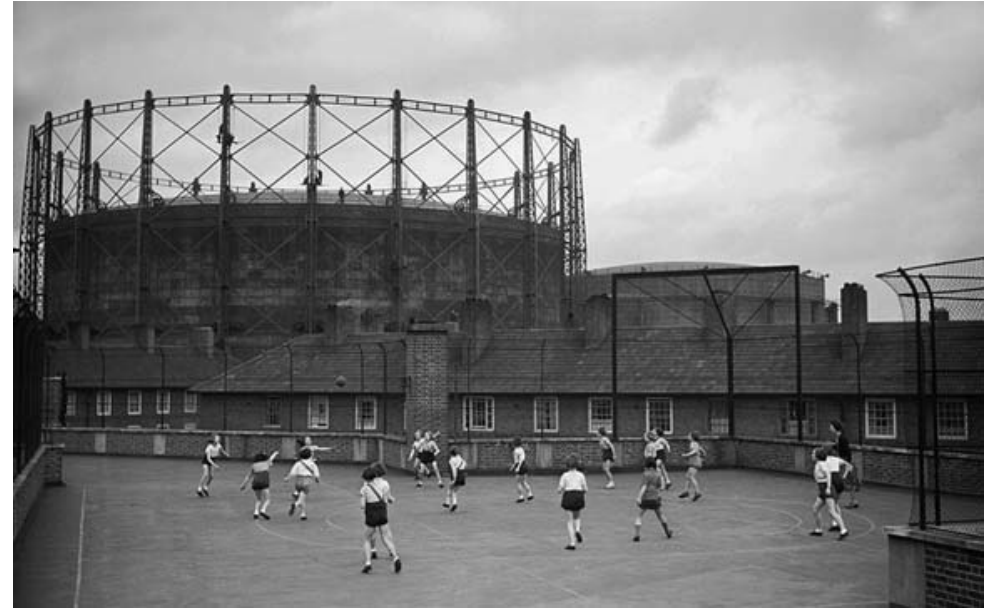

Gasómetro de Kennington (Keep Pe School) (1946), UK (fuente: (C)The Guardian, pinterest)

Gasómetros de Bethnal Green 1858, Londres, Museo de la Ciencia, Getty Images. debatido su estudio y recuperación, y también, donde cuentan con el mayor número de ejemplos (Johnson 2013).

La historia de los gasómetros es muy larga: casi doscientos años en relación con las distintas etapas de la Revolución Industrial (Hobsbawn 1977a, 1977b, 1998). La etapa en la que nos centraremos, sin embargo, es la denominada "clásica": en primer lugar, porque es la época de esplendor de estas instalaciones y en segundo, por el número de ejemplos que se levantaron por todo el mundo. La época clásica comprende desde finales del siglo XIX hasta mediados del siglo XX. ${ }^{10}$

Los primeros gasómetros eran simples silos de fábrica, cilindros cubiertos por cúpulas, resueltos como edificios convencionales: con ventanas seriadas o ciegos, y adaptados a la escala residencial en la que se situaban. A principios del XIX se construye el primero conocido: el de la Torre de Londres (1807). De estos primeros tipos no quedan apenas ejemplos, aunque determinaron -en la forma- un tipo posterior: el de los gasómetros rígidos o sin agua. ${ }^{11}$

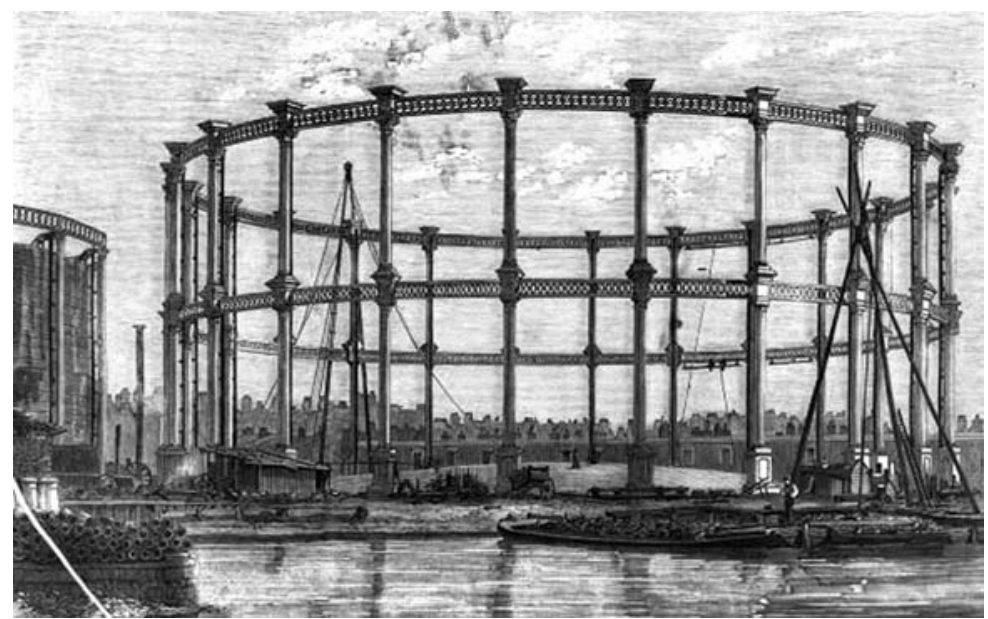

Estos primeros depósitos enseguida evolucionaron hacia el tipo telescópico, que se adaptaba mejor a su funcionamiento: aumentar/disminuir el volumen según la cantidad de gas almacenada. Y cuyo control (a partir de la presión o altura de agua) era más fácil que en los rígidos. El primero conocido es de 1824 y se levantó en Leeds (Reino Unido). Este tipo constaba de una estructura exterior metálica sobre la que se colocaban unas guias o raíles que permitian desplegar hasta cuatro porciones telescópicas. El depósito se situaba dentro de un tanque de agua, sobre el que se desplegaban las diferentes porciones. El principio de funcionamiento es sencillo: la mayor densidad del agua actúa como material sellante y controla la presión del gas (que funciona con la altura de la columna de agua).

Este tipo dio lugar a una variante: el depósito telescópico de guías espirales, que permitía desplegar las secciones una sobre otra sin necesidad de una estructura auxiliar. De este tipo el primero construido fue en 1890 en Northwich (UK) (Russel 2015).

El sistema telescópico se demostró muy eficaz y fue el más comúnmente usado en todo el Reino Unido hasta 1983, año en el que se construyó el último gasómetro de guías helicoidales (Russel 2015).

En el período de mayor desarrollo, ${ }^{12}$ la firma inglesa Cutler $\&$ Sons, ${ }^{13}$ llegó a construir centenares de gasómetros por toda Inglaterra, tecnología que luego extendió por todo el Imperio Británico y popularizó en el resto de Europa. ${ }^{14}$ La patente de esta firma desarrollaba un sistema telescópico que comprendia una estructura fija (o en columna) triangulada por medio de un ingenioso sistema de barras, cartelas y roblones, sobre la que se desplegaban hasta cuatro pisos de depósitos, soportando en total más de mil toneladas. El diseño de la estructura se encargaba a diferentes ingenieros, de forma que nunca se trataba del mismo modelo -paradojas de la industrialización-, lo que los convirtió en piezas únicas, con decoraciones clásicas (capiteles, triangulaciones, remates) y detalles distintos, 15 aunque siempre con esa característica imagen de tela de araña resaltada por C. Costelloe, presidente de la influyente Victorian Society, una de la instituciones que más ha hecho por su conservación. ${ }^{16}$

El sistema telescópico ha sido usado durante más de cien años y desarrollado especialmente en el área anglosajona, pero en 1920 hacen su aparición los gasómetros secos, también llamados de Wiggins. ${ }^{17}$ 
Son depósitos fijos que albergan un tanque controlado por un sistema hidráulico de pistón, cuya altura (o presión) se encarga de controlar la entrada y salida del gas. $\mathrm{Su}$ capacidad es mucho mayor que en los telescópicos -motivo por el que se impusieron- y además la presión del gas se somete a un rango más amplio, por lo que el control sobre la red y la distribución es también mayor.

Del gasómetro sin agua derivan los gasómetros tipo M.A.N. que han sido los más populares en Alemania, junto a los de tipo Klönne, Leffer y Thyssen. ${ }^{18}$ Del gasómetro de pistón se ha valido principalmente la industria alemana, hasta el punto de ser como en el caso de la inglesa- el icono de su propia Revolución Industrial. La recuperación de estos gasómetros ha seguido en general, unas pautas distintas a las de la sociedad inglesa, principalmente de promoción privada, frente a la de la promoción pública del resto de Europa. Es decir, en Europa -excepto en Gran Bretaña- la iniciativa, financiación y destino de estos depósitos ha estado en manos de la administración o de instituciones vinculadas al poder politico.

La obsolescencia del uso del carbón como fuente de energía ha terminado con estas instalaciones. Obsolescencia debida al cambio de gas ciudad a gas natural, introducido a partir de 1960 en la mayoría de los países. ${ }^{19}$ Los yacimientos de gas natural, menos contaminante y más fácil de obtener, junto con el desarrollo de redes cada vez más eficaces, hacen innecesario los antiguos gasómetros. Las nuevas infraestructuras gasísticas son redes de carácter transnacional de miles de kilómetros, que permiten almacenar gas suficiente a lo largo de su recorrido. Junto a los nuevos materiales y los sistemas de regulación y control de la presión, los actuales

am, Lond Bayley/REX) gaseoductos no precisan apenas de depósitos.

De manera que los gasómetros, después de siglos de servicio, han dejado de ser útiles, lo que ha llevado al desmantelamiento de muchos de ellos, la inmensa mayoría. La reacción no se ha hecho esperar principalmente en Europa: Reino Unido, Alemania, Francia e Italia, donde representan una etapa histórica vinculada al desarrollo de sus respectivas sociedades. En otros países como USA, Australia, o Canadá, la industria ha estado históricamente más vinculada al recurso del petróleo, por lo que nunca hubo un gran número de estas instalaciones. En estas sociedades hace tiempo que desaparecieron.

La situación en Europa es muy diversa porque ha dependido de la consideración del Patrimonio Industrial en los distintos países. Organizaciones como el TICCIH,20 la Victorian Society, ${ }^{21} \mathrm{u}$ otras organizaciones locales, -sociedades formadas en torno a la preservación de algún ejemplo concreto- han hecho mucho en la recuperación de estos contenedores. ${ }^{22}$ En líneas generales puede decirse que la puesta en valor del Patrimonio Industrial, tiene un fuerte arraigo en países con una larga tradición industrial (Reino Unido, Alemania, Países Bajos) y menor en países no tan industrializados o con una industrialización más tardía (España, Italia).

La estrategia que ha demostrado ser más eficaz ha sido la de estudiar caso por caso, y analizar el ejemplo concreto: situación, estado de conservación, simbolo cultural y compromiso ciudadanos. Y con estos elementos proyectar una recuperación sostenible.

Un ejemplo destacado de todo lo anterior y con todos estos ingredientes (símbolo cultural, etapa histórica, reconocimiento ciudadano), es el de la recuperación de los gasómetros de la cuenca del Ruhr, el antiguo Zollverein, que constituye por sí mismo un modelo sobre del que pueden obtenerse interesantes conclusiones.

\section{Zollverein: una recuperación integral}

El nombre de Zollverein significa "Unión Aduanera", y viene del acuerdo que en 1834 algunos estados de Alemania (liderados por Prusia) forman para favorecer el comercio y la industria entre sus miembros. Esta unión es el precedente más claro de la subsecuente unión política, producida en 1871. De estos hechos se derivan la potenciación de un área fuertemente industrializada en la llamada cuen- 
Mapa del Ruhr (fuente: Cuenca del Ruhr, wikipedia)

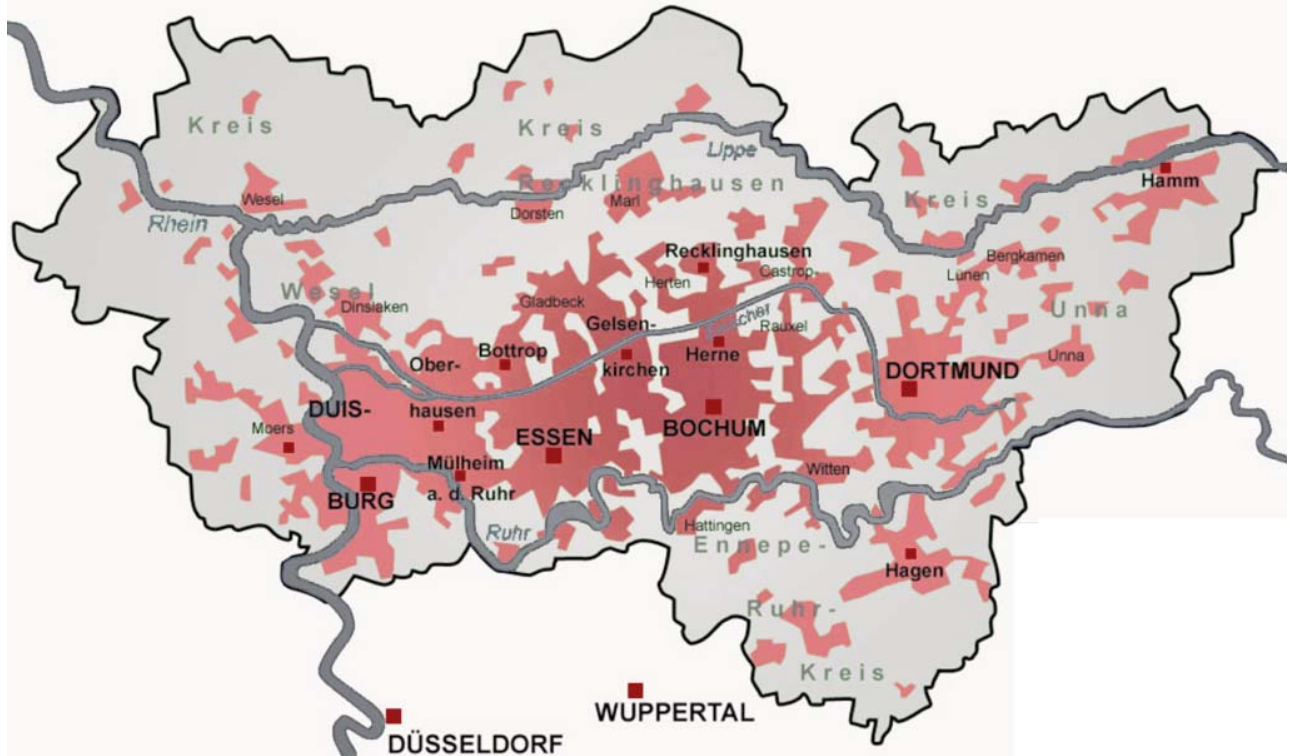

ca del Ruhr, entonces en desarrollo, situada al noroeste de Alemania en el estado de Renania-Westfalia. La zona del Ruhr alcanza en 1913 el primer lugar entre las regiones industrializadas del planeta (Gläßer et al. 1997), preponderancia que recuperó solo después de la Segunda Guerra Mundial -aunque dejó de ser la primera del mundo- fundando en 1951 la Comunidad Europea del Carbón y del Acero (CECA), precedente de la actual Unión Europea.

La región tiene una extensión de 3484 kilómetros cuadrados con una población de más de cinco millones de habitantes. A las fábricas de acero y la minas de carbón que configuran su paisaje, se suma el hecho de ser una conurbación de ciudades: Essen -la capital de la regiónBochum, Dortmund y Duisburg, son las mayores (cerca de medio millón de habitantes), en torno a las cuales existe una constelación de ciudades menores, la mayoria nacidas alrededor de una fábrica, una mina de carbón o ambas. ${ }^{23}$ La región limita al sur con el área de Düsseldorf, y al norte con la de Münster, ciudades mucho más influyentes que ninguna de las anteriores, pero de mucho menor desarrollo industrial.

El resultado de más de un siglo de constante desarrollo industrial -desde las primeras fábricas a mediados del XIX, ${ }^{24}$ hasta los años sesenta del siglo XX- lo forma un área que por identificación con la antigua unión se ha dado en llamar Zollverein y que coincide aproximadamente con la región del Ruhr. A partir de los años sesenta, la obsolescencia del carbón y la siderurgia, marcó el comienzo de una transformación que llega hasta la actuali- dad. La recuperación del ingente Patrimonio Industrial existente (fábricas, estaciones de ferrocarril, puertos fluviales, gasómetros, etc) y las enormes -y abandonadas- minas de carbón a cielo abierto, fueron los hitos para el desarrollo de la gran "industria cultural" existente en la actualidad. En este contexto es donde se entiende que la mina de Zollverein por ejemplo, situada al norte de Essen, fuera declarada en 2001 Patrimonio de la Humanidad por la UNESCO. ${ }^{25} \mathrm{La}$ "mina más bella del mundo" -que es como se la conoce-26 y toda la cuenca del Ruhr constituyen hoy en día una zona turística que ha utilizado como reclamo su potente historia industrial, convirtiéndose en un área musealizada sobre la época de la Revolución Industrial conocida como "clásica". 27 El lema "Erhalt durch Umnutzung" (Mantenimiento para el disfrute), 28 ilustra una declaración de principios para una zona cultural y de ocio de las mayores de Europa. En este contexto, junto a las fábricas y las minas, destacan por su condición de hitos los gasómetros.

En la cuenca del Ruhr los gasómetros eran innumerables: se encontraban en todas las minas de carbón, y en muchos de sus cientos de fábricas. En Dortmund, por ejemplo, había quince catalogados, 29 y el mismo número en Essen. En Geselkirchen, por ejemplo, se encontraba el mayor gasómetro de Europa: construido entre 1937 y 1939, era del tipo Klönne (es decir de pistón), con una capacidad de 600.000 metros cúbicos, de 147 metros de alto y diámetro de 80 metros. Este imponente depósito fue demolido en 1940.

La mayoría de estos gasómetros eran modernos: construidos desde los años 
Mina del Zollverein, Alemania (fuente: (C)Bernd y Hilla Becher)
Gasómetro de Oberhausen (1929), Alemania (fuente: Cruhrfoto.net)

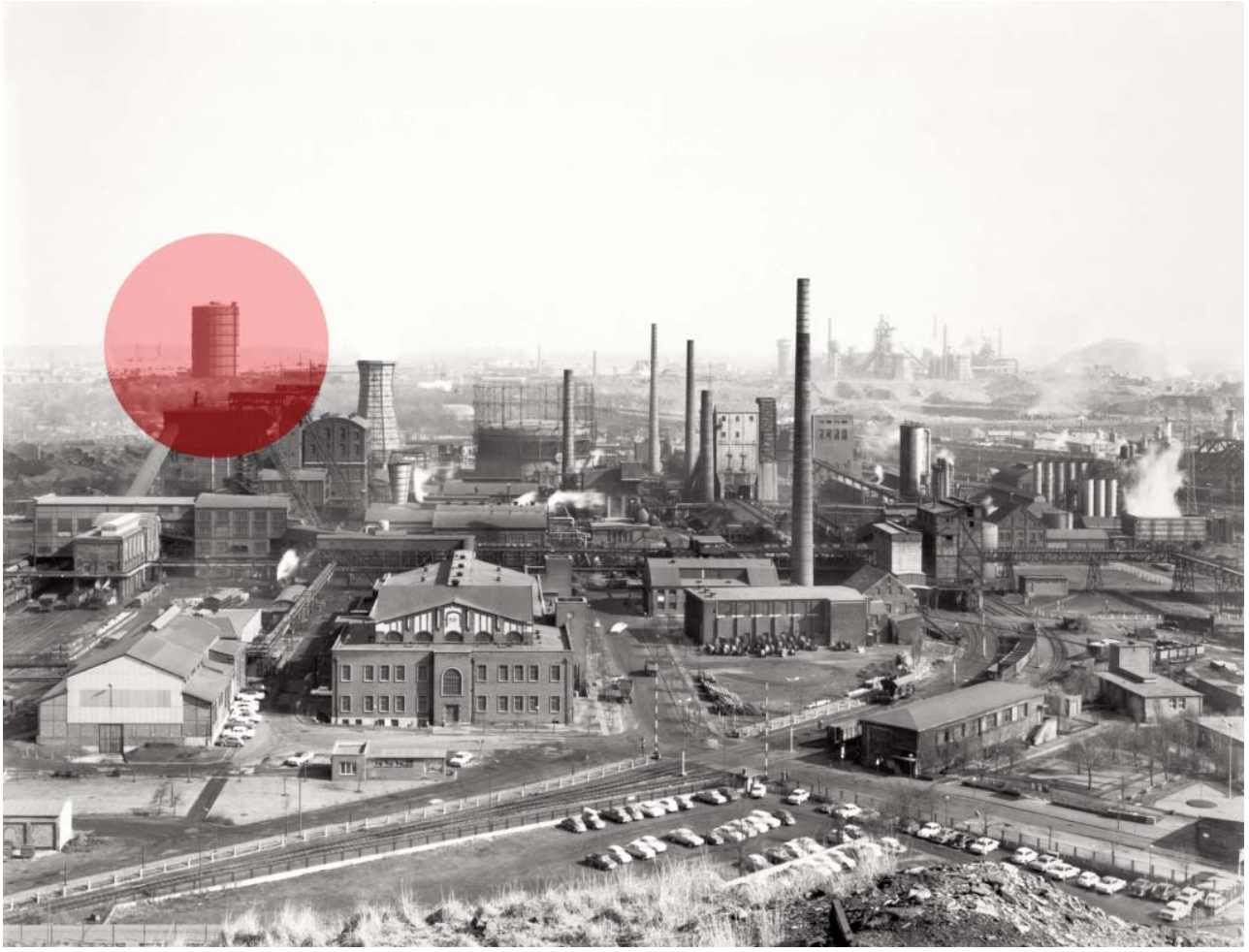

veinte y hasta los cincuenta del siglo anterior, ${ }^{30}$ y totalmente funcionales: depósitos para almacenar la producción de las fábricas de carbón. Los más característicos eran del tipo seco o de pistón (Scheibengasbehälter) construidos bien con la patente M.A.N. Klönne, Leffer o Thyssen. ${ }^{31}$ Pero también del tipo rígido o de campana (Glokengasbehälter) y telescópicos (Teleskopgasbehälter). De todos ellos existian innumerables variantes o modelos.

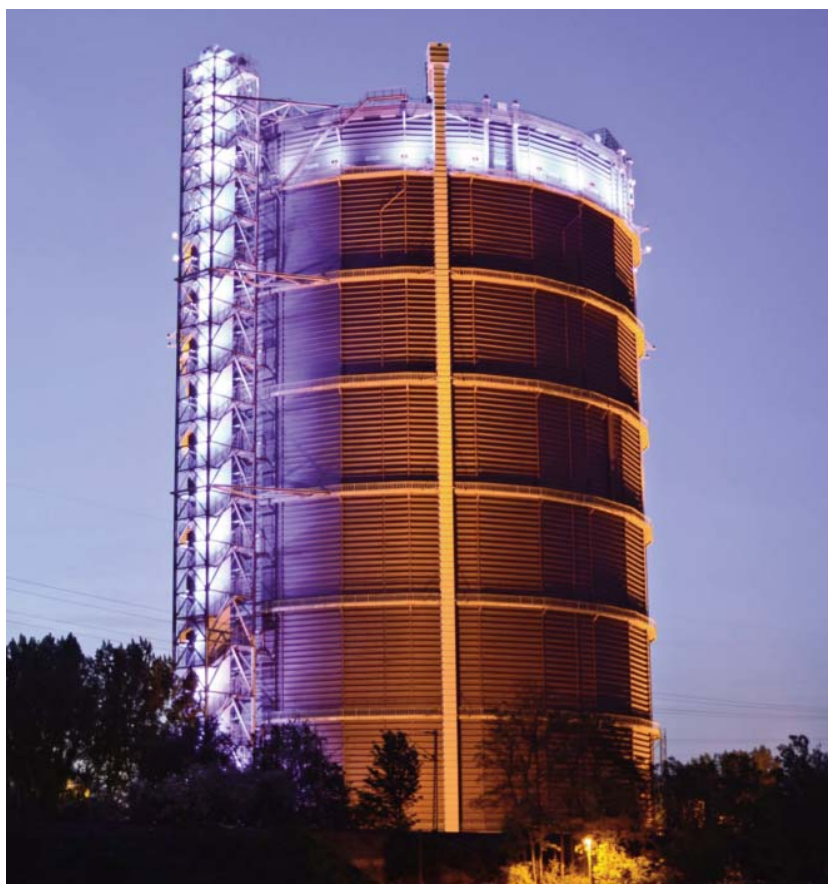

En la actualidad algunos todavía siguen en funcionamiento: generalmente son los de tamaño más reducido y con algún tipo de presión (Mitteldruck, media presión o Hochdruck, alta presión).

Los mayores y más singulares están conservados y protegidos bajo la catalogación de monumento (Denkmalschutz), ${ }^{32}$ y son los de Oberhausen, Münster, Dortmund, Duisburg y Wuppertal, todas ellas ciudades de la cuenca del Ruhr o en su área de influencia. ${ }^{33}$ Pero también existe toda una constelación de gasómetros menores en ciudades como Bochum, Botropp, Geselkirchen o Essen. La repetición de estos elementos en el perfil de las ciudades y caminos se ha convertido en una seña de identidad de la región, una auténtica Denkmal (es decir, Landmark) en el paisaje. ${ }^{34}$

Los rasgos distintivos de la singular reconversión de estos elementos del Patrimonio Industrial de la zona del Ruhr, han seguido una serie de pautas que pueden rastrearse en los siguientes ejemplos.

\section{Casos de estudio}

\section{Gasómetro De Oberhausen}

Oberhausen es una población en la cabecera del río Ruhr, casi en su desembocadura con el Rhin. Por su situación es la primera y más importante población en la región desde la frontera con Francia. Este carácter fronterizo ha sido determinante en la recuperación del gasómetro. 
Gasómetro de Oberhausen Interior (1929), Alemania (fuente: Oruhrfoto.net)

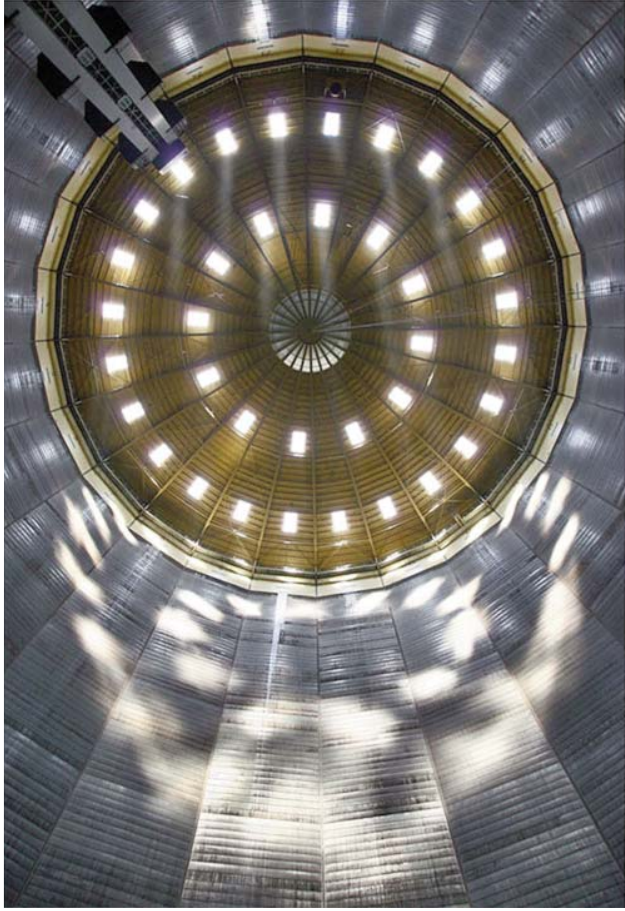

El gasómetro de Oberhausen fue reconvertido entre 1993-94 y exploró algunas pautas de intervención, que luego han sido adoptadas para este tipo de actuaciones. Es el mayor gasómetro conservado en la actualidad en Europa. Fue construido en 1929, y destruido completamente (excepto la base) durante la guerra. En 1949 fue reconstruido nuevamente, como un gasómetro de pistón del tipo M.A.N. con una altura de 117 metros y un diámetro de 68 metros, sobre una base poligonal de veinticuatro lados, de estructura metálica y cerrado con chapa de acero. Su capacidad fue de 347.000 metros cúbicos y se mantuvo en funcionamiento hasta 1988.

El disco o pistón pesaba 600 toneladas y subía hasta los 97 metros de altura, con lo que la presión para su funcionamiento alcanzaba las 1200 toneladas.

En el proyecto de reconversión se colocó el pistón a 4,5 metros de altura para crear un hall de 3.000 metros cuadrados como espacio de acogida y exposiciones. El resto del cilindro sobre dicho vestíbulo, es un espacio de 7000 metros cuadrados y 90 metros de altura, que alberga un impresionante espacio interior -conocido como la catedral de la industria (ref web 7)- dedicado a artes plásticas y escénicas, donde se han realizado espectáculos y exposiciones que potencian sus cualidades espaciales con instalaciones de artistas como Christo \& Jeanne Claude o Bill Viola (ref web 8).

El gasómetro de Oberhausen es un ejemplo de actuación pública destinada a acti-

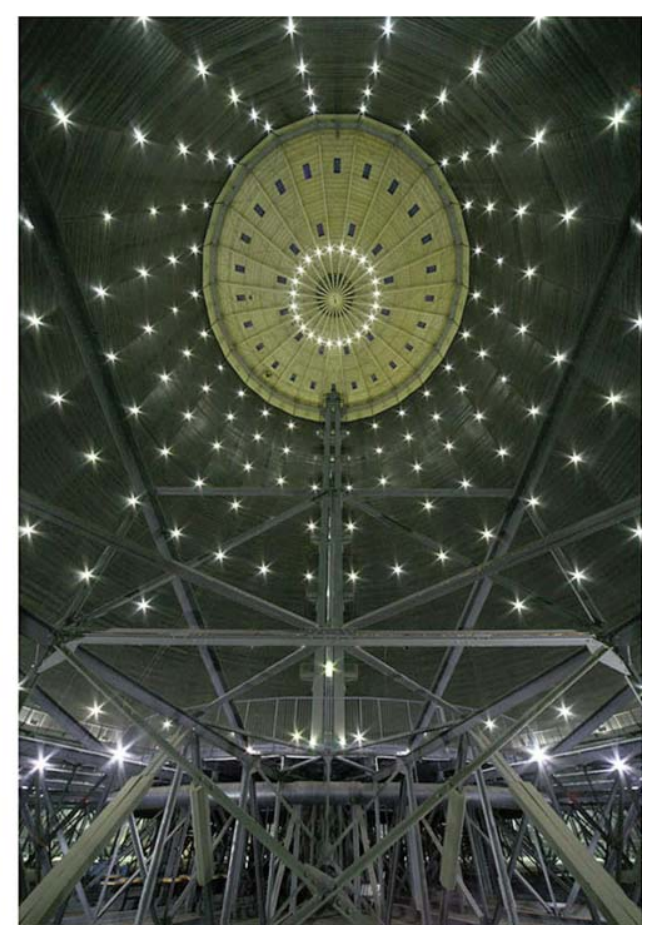

var un cambio de uso para apoyar una incipiente industria cultural. Como hito en el paisaje su potencia es incuestionable. Funciona como anuncio y entrada, como reclamo de las actividades que tienen lugar en todo el Zollverein: itinerarios, museos, exposiciones y eventos culturales pero sobre todo como simbolo de una transformación.

En la actualidad el gasómetro de Oberhausen es el centro de la actividad cultural que tiene lugar en la zona del Ruhr y uno de los hitos principales del itinerario de la ERIH (Europäischen Route der Industriekultur), 35 entre los que se encuentran los hitos industriales más importantes de Europa. Fue declarado Patrimonio Cultural de la Unesco en 2011.

\section{Gasómetro de Dortmund}

Dortmund es una de las ciudades más importantes del Ruhr. Contaba con el mayor número de gasómetros de la región, de los que en la actualidad solo resta uno.

El gasómetro de Dortmund es menor que el de Oberhausen: 76,5 metros de altura, 40 metros de diámetro y 120.000 metros cúbicos de volumen. Es del tipo de pistón (Scheibe) pero de patente Klönne. Su fecha de construcción se sitúa en los años cincuenta pero quedó en desuso a partir del año 1998/99 cuando se cerraron los altos hornos de la inmediata fábrica Hoesch.

Fue declarado monumento (Denkmalschutz) en 2002 e incluido en el itinerario 

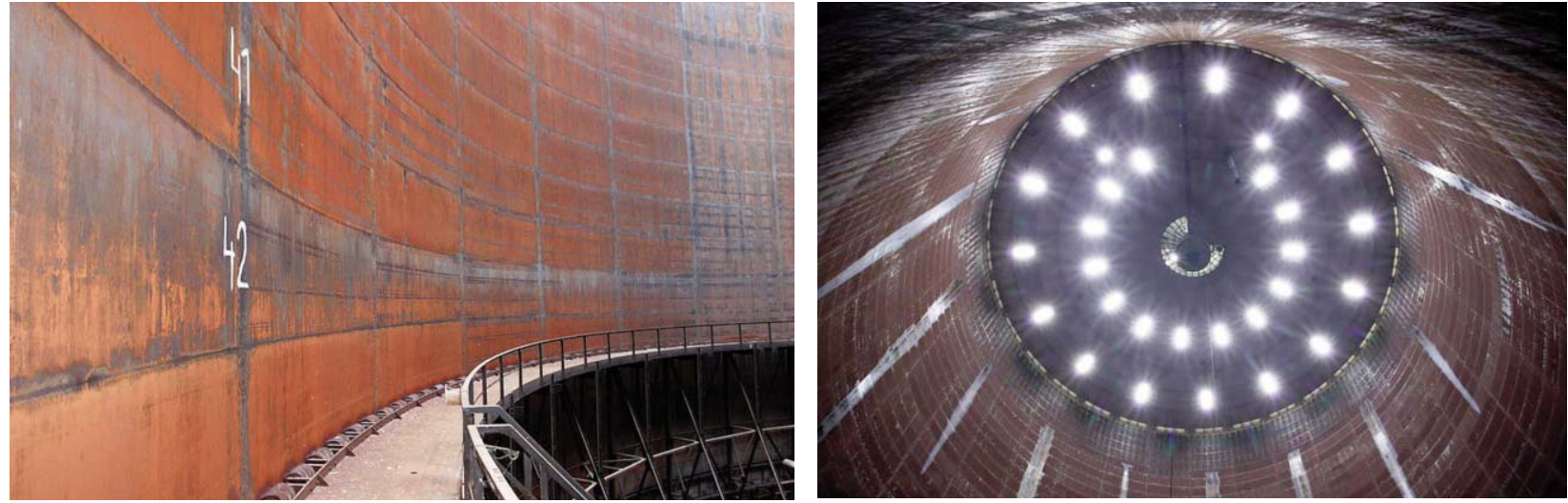

Gasómetro de Dortmund, Interior, Fábrica Hoesch (1950), Alemania (fuente: ruhrfoto.net)

Izquierda. Gasómetro de Duisburg Interior Fábrica Thyssen (1950), Alemania (fuente: ruhrfoto.net)

Derecha. Gasómetro de Duisburg Exterior Fábrica Thyssen (1950), Alemania (fuente: ruhrfoto.net)
ERIH. Se encontraba sin uso hasta hace un año, cuando el club de escalada nacional lo ha adquirido para instalar su local de entrenamiento en su impresionante cilindro interior (ref web 9). Se trata de una iniciativa privada muy interesante: la recuperación del depósito histórico para equipamiento deportivo y que ha iniciado un camino que han seguido otros muchos gasómetros del Ruhr, como es la inteligente conciliación del interés particular con el interés público, característica de las culturas del norte de Europa a lo largo del Siglo $\mathrm{XX}$

\section{Los gasómetros de Duisburg}

Esta ciudad es junto a Dortmund o Essen una de las más importantes del Ruhr, pero en la que -al contrario de éstas- la industria siderúrgica todavía mantiene algunas fábricas con sus correspondientes gasómetros. En la actualidad siguen en pie ocho, de los que cuatro todavía están en funcionamiento (en las fábricas Thyssen), tres cerrados y solo uno recuperado.

Este gasómetro recuperado es el más antiguo: data de 1920 y es del tipo telescópico. La altura de su estructura es la de un edificio de 8 plantas y su diámetro tiene 45 metros. El volumen original era de 20.000 metros cúbicos.
En el año 1996-98 fue recuperado para practicar el submarinismo. Un club deportivo instaló una piscina de entrenamiento bajo su cúpula original (una estructura de arcos rebajados, triangulada y roblonada) y ha conseguido convertirlo en un espacio deportivo de referencia. El mantenimiento del tanque de agua y su transformación en estanque-piscina es una hermosa referencia a un espacio clásico -los antiguos aljibes de agua- a lo que hay que añadir la rotundidad del espacio circular reflejado en la cúpula. El agua además hace referencia a su antigua tecnología conectando su uso actual con su memoria.

También la escalada -sobre su estructura de tela de araña de la parte área- tiene lugar en el volumen exterior de este equipamiento deportivo. Por lo que se ha convertido en un elemento de referencia ciudadana.

También en Duisburg, el grupo de tres gasómetros de la fábrica de acero en Bruckhausen componen el perfil de la siderurgia Thyssen: dos cilindros de más de 100.00 metros cúbicos y un tronco de pirámide de 90.000 metros cúbicos, todos ellos de pistón y de patente Thyssen/Leffer. Lo interesante en este caso es que siguen funcionando como tales, ya que los altos hornos Thyssen mantienen su producción en la actualidad. El funciona-
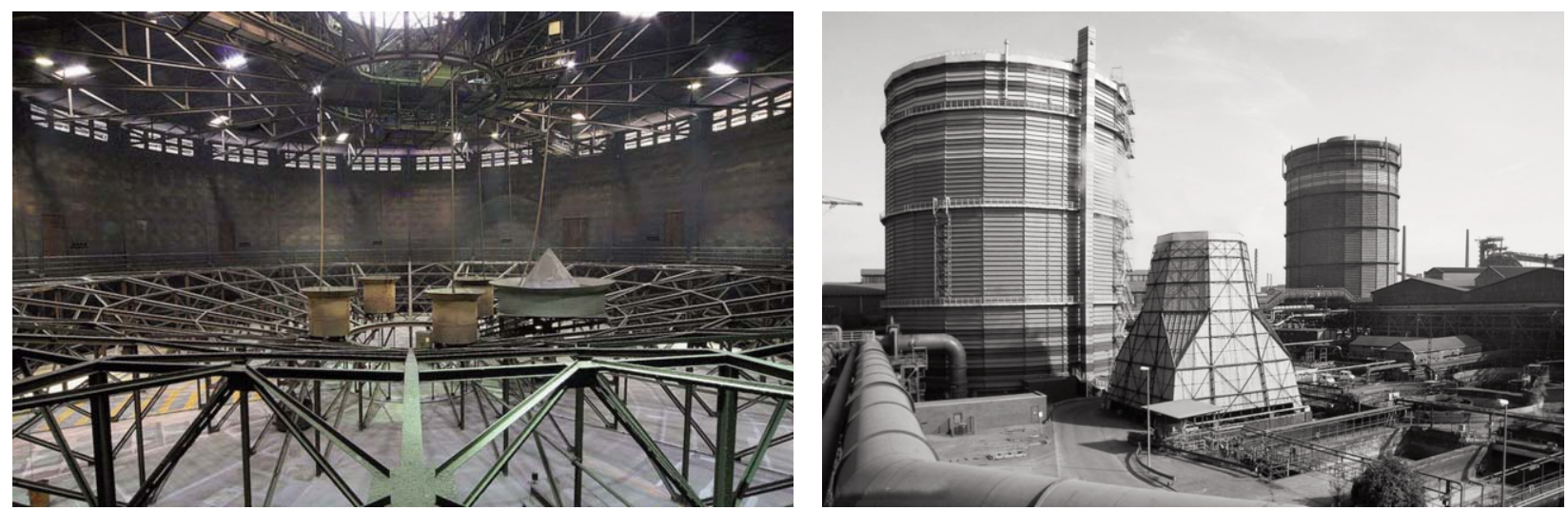
miento de la fábrica y sus gasómetros constituye un espectáculo en sí mismo, un simbolo de la otrora potente industria pesada.

\section{Gasómetro de Münster}

Este depósito no se encuentra estrictamente en el área del Zollverein, pero Münster es una ciudad de enorme influencia en la región por su tradición cultural: universidad, bibliotecas y museos componen su actividad principal.

El gasómetro de Münster era un modelo de pistón del tipo Klönne. Fue construido muy tardiamente, entre 1953/54, de 52 metros de altura y 56 metros de diámetro. Su volumen tenía 65.000 metros cúbicos. Lamentablemente su cúpula y el depósito telescópico se desmontó en 2005, aunque se llegó a tiempo para conservar el tanque de agua y la estructura exterior. Fue declarado monumento (Denkmal) en 2005.

En la actualidad, su estructura abierta se utiliza en representaciones teatrales y exposiciones al aire libre, a la espera de un destino más concreto (ref web 10).

\section{Gasómetro de Wuppertal}

Tampoco Wuppertal pertenece al área del Ruhr, pero es una ciudad muy próxima y cuya influencia como foco cultural es importante en la región. Wuppertal está considerada a nivel global, una ciudad de referencia en las artes escénicas y la música. El gasómetro es el logo de la ciudad.

Izquierda. Gasómetro de Wuppertal, Interior Alemania (fuente: www.stahlfoto.net)

Derecha. Gasómetro de Wuppertal, Exterior, Alemania (C) Oliver

Frühschütz2013)
El gasómetro de Wuppertal es de 1950-52, aunque fue protegido y preservado en 1997. En la actualidad todavía no ha sido declarado monumento (Denkmalschutz). Es del tipo M.A.N. y tiene un volumen de 60.000 metros cúbicos. Levantado sobre una base poligonal de 20 lados recuerda por diseño al de Oberhausen, aunque es mucho menor.
Recientemente, en 2015, ha sido adquirido para albergar un centro deportivo, siguiendo la pauta del de Dortmund o Duisburg.

\section{Conclusiones}

Las características que como hemos visto reúnen todos los casos de estudio anteriores se podrian resumir en las siguientes conclusiones:

1. Los gasómetros del área del Zollverein o cuenca del Ruhr tienen unas pautas morfológicas determinadas: son del tipo seco o de pistón y de patente alemana (es decir con una tecnología propia). Están circunscritos a esta área concreta.

2. El diseño sigue un patrón industrial: cilindros construidos como prismas poligonales (más sencillos de ejecutar a partir de elementos planos), modulación del volumen, estructura estandarizada y cerramientos de chapa, es decir: seriación y economía.

3. El "carácter público" de las actuaciones de recuperación sobre estos contenedores, es decir su promoción desde el poder político para usos comunitarios. Si bien ha existido contestación ciudadana en algunos casos, la implicación social no ha sido muy determinante, quizá al estar interiorizado su carácter industrial como un hecho histórico y cultural por parte de la población. La promoción por la iniciativa privada se ha planteado también para fines comunitarios (deportivos o de ocio), lo que indica el carácter social de estas actuaciones.

4. De este carácter público se deriva que muchos gasómetros se hayan recuperado como "contenedores culturales". Contenedores convertidos en hitos de una potente industria cultural de turismo y servicios, en los que trabaja en la actualidad la población -también reconvertida- de la otrora industrial cuenca del Ruhr.
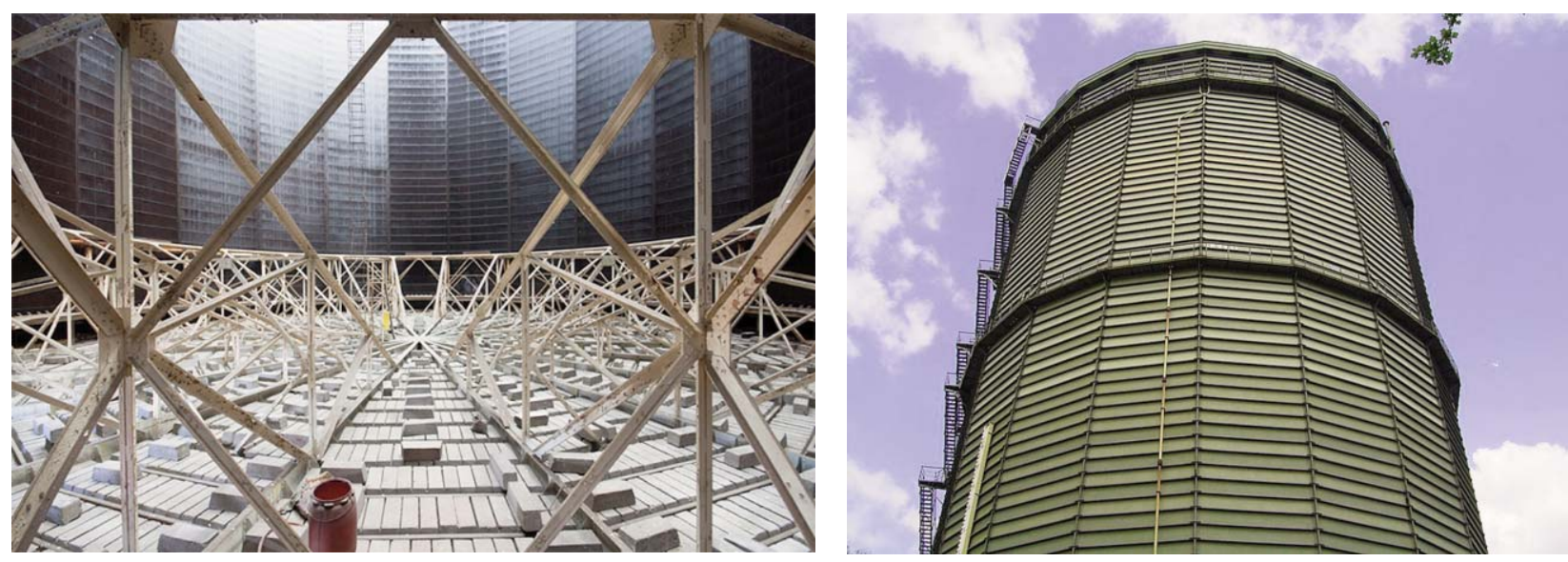
5. A diferencia de otros casos europeos, donde tan solo la estructura metálica exterior se ha conservado integrada en espacios verdes apenas como un elemento mobiliario, totalmente descontextualizado e irreconocible de su función original (son, por ejemplo los gasómetros de King Cross en Londres, de Ostia en Roma o el gasómetro de Barcelona), los casos alemanes del Ruhr, muestran ejemplos de reconversiones correctas e inteligentes, que han sabido preservar buena parte de su configuración original, pero dotándola de un nuevo sentido con programas compatibles con su memoria industrial.

\section{Notas}

1. Zollverein es el nombre de la mina de carbón de Essen declarada Patrimonio por la Unesco en 2001, a su vez tomado del nombre que se daba a esta región por constituir una zona de libre mercado (Unión Aduanera 1850)

2. Este periodo se podría denominar como la época clásica de los gasómetros, donde se fijan sus características fisicas y materiales

3. M.A.N. SE, Maschinenfabrik Ausburg-Nürnberg Societas Europea, la fábrica de motores alemana con sede en Munich, que patentó un tipo de gasómetro seco de pistón, que se construyó por toda Alemania.

4. "Telas de araña únicas", según expresión de C. Costelloe, director de la Victorian Society, institución comprometida con su conservación (Ram 2015)

5. S. O' Carroll ingeniero y documentalista, se refiere a esta cualidad de los gasómetros: "I would sit in the back of my parents' car as we drove down the motorway and wonder at the size of them -sometimes filled with a massive column, sometimes mysteriously empty and see-through." (Iba sentada en el coche de mis padres mientras pasábamos por la autopista y me asombraba de su tamaño: algunas veces llenos con una columna masiva, otras misteriosamente vacíos para mirar a través) (Ram 2015). Traducción autor.

6. Esta definición se aplica a los construidos entre finales del XIX y principios del XX. Ver nota 2.

7. En Inglaterra en concreto existe un movimiento social, dentro del cual se encuentra la Victorian Society que se ha preocupado de su mantenimiento a lo largo de todo el país. Ver: www.victoriansociety.org.uk

8. K. Johnson planificador urbano del Nationa Grid -compañia del gas británica- dice: "It's true that they have been part of the community in the past, but that value has now gone." (Es cierto que fueron parte de la comunidad en el pasado pero su valor ha desaparecido) (Ram 2015). Traducción autor.

9. William Murdoch (1754-1839) ingeniero e inventor escocés, Samuel Clegg (1781-1861) ingeniero inglés que desarrolló el uso del gas y Antoine Lavoisier (1743-1794) químico francés y fundador de esta ciencia.

10. 1875-1914

11. Ver nota 15

12. Desde 1875 hasta 1914 , ver nota 7 , o segunda etapa de la revolución industrial.

13. Samuel Cutler \& Sons, (1844-1923), firma de ingeniería británica que construyó entre otros, los célebres gasómetros de Poplar holder station (1876-78), Bethnal Green $(1866,1889)$, Kingston gasholders (1880), Hornsey Park (1888) y otros por todo el Reino Unido, y también varios en Italia (gasómetro de Turin), Francia y Alemania.

14. Ver un ejemplo en nota 20.

15. Ver el diseño de los gasómetros King Cross (1850-1883) (Ref web 1)

16. "It reflects the beating of a human heart on a city scale, they were a reminder of a city's vitality." Ver nota 1. "Our industrial past is becoming less and less visible, People see things that have been around at the same time as Dickens and Engels and it gives them a sense of connection with the past." "Its not just their history that makes them special. Primarily they are beautiful structures - if they are new and built today they would retain that quality, and we'd want to keep them. It's the spider's web of iron that makes them unique." (Ram 2015)

17. J.H. Wiggins inventor en 1936 de una patente para almacenar gas, cuyo sistema se basa en estos principios (Prieto 2014).

18. Ver Nota 1.

19. El uso de gas natural proviniente del Mar del Norte se introdujo en Inglaterra a partir del descubrimiento de yacimientos en 1965. En Alemania y Europa central el gas viene desde Rusia y España, por ejemplo, lo importa de Argelia. 20. Samuel Cutler \& Sons, (1844-1923), firma de ingeniería británica que construyó entre otros, los célebres gasómetros de Poplar holder station (1876-78), Bethnal Green (1866,1889), Kingston gasholders (1880), Hornsey Park (1888) por todo el Reino Unido y también en Italia (gasómetro de Turin), Francia y Alemania.

21. La Victorian Society fue fundada en el Reino Unido en 1958 para promover y proteger la arquitectura victoriana y eduardiana (construida entre 1837 y 1914). Es sociedad consultora para el catálogo de edificios protegidos (Statutory List of Buildings). Entre sus fundadores encontramos a John Betjeman, Henry Russell Hitchcock y Nikolaus Pevsner. (Ref web 2).

22. La protección del gasómetro de Oviedo fue fruto del activismo de una sociedad civil local en 2011. De los tres gasómetros de Avilés uno fue desmontado en 2012 permaneciendo los otros dos

23. La región del Ruhr sigue siendo en la actualidad una de las mayores productoras de lignito de mundo. Fuente: World Economic Outlook Update 2016 (ref web 3).

24. La industrialización en Alemania comienza más tarde que en Reino Unido y Francia, y no se produde hasta la unión económica primero (1834) y politica después (1871).

25. La mina de Zollverein, Welterbe Zollverein, es la única de esta categoría declarada Patrimonio de la Humanidad por la Unesco. La cuenca del Ruhr cuenta con más de un centenar de minas, siendo Zollverein la mayor (ref web 4).

26. En la memoria de la declaración como patrimonio de la Unesco, Zollverein es calificada con estas palabras: Schönste Zeche der Welt (La mina más bella del Mundo).

27. Es decir, las dos etapas definidas por Hobswan. Ver notas 10 y 14 .

28. Lema del complejo cultural de Oberhausen (ref web 5).

29. En la actualidad demolidos

30. La introducción del gas natural se produce más tarde hacia los sesenta.

31. Todas estos tipos se deben a ingenieros alemanes que desde principios del XX realizaron patentes sobre el tipo de pistón (Klönne c.1930).

32. Denkmalschuz significa protección monumental

33. Münster y Wuppertal no pertenecen a la cuenca del Ruhr, pero sin embargo están en su área de influencia.

34. El itinerario ERIH, Europäischen Route der Industriekultur, tiene a los gasómetros como hitos de sus etapas (ref web 6).

35. European Route of Industrial Heritage (1315 sitios en 45 paises) (ref web 6). 


\section{Bibliografia}

Gläßer, E.; Schmied, M. W.; Woitschützke, C.P. 1997. Nordrhein-Westfalen, Justus Perthes Verlag Gotha.

Hobsbawn, E. 1977a. La era de la revolución: Europa 1789-1848. Barcelona, Crítica.

Hobsbawn, E. 1977b. La era del capital: 1848-1875. Madrid, Guadarrama.

Hobsbawn, E. 1998. La era del imperio: 1875-1914. Barcelona, Crítica.

Johnson, D. 2013. Gasometers: a brief history. The Telegraph, 26/11/2013.

Klönne, August. Circa 1930. Kolbengasbehälter. Dortmund. Firmenschrift undatiert.

Le Corbusier y P. Jeanneret. 1926. Cuatro composiciones. Oeuvre Complete. Birkhäuser, ed. 1999.

Le Corbusier. 1923. Hacia una arquitectura, Ed. Poseidón, Buenos Aires, 1964, p. 67.

Prieto, E. 2014 . Gasómetro. Patente, US 2050685. Tectónica. 15 de febrero de 2014.

Ram, Ed. 2015. Will the UK's gasometers be missed? $B B C$ News, 9/02/2015. Magazine online. http: / / www.bbc.com / news / magazine30405066.

Bibliografia complementaria no citada en texto

Fiorino, L.; Landolfo, R.; Mazzolani, F. 2015. The refurbishment of gasometers as relevant wittness of industrial archaeology. Engineering Structures, 84.

Klönne, A. 1939. Der größte Gasbehälter der Welt, Wasserloser Gasbehälter, DRP. Firmenschrift, Dortmund.

O'Hagan, S. 2015. Gasworks wonders. The Guardian, 14 June.

Scheibengasbehälter M.A.N. Firmenprospekt, Dortmund, 1958

Schmid, N.J.(ed). 2001. Archiv Gasometer: Das neue Wiener Stadt-und-Landesarchiv. Schmid Verlagsges.

Sorapure, D.; Strawbridge, M. 2014. Kingston Gasholders. Museum of London Archaelogy, enero.

\section{Referencias web}

Ref web 1. https://www.kingscross.co.uk/gasholder-8. Ref web 2. www.victoriansociety.org.uk

Ref web 3.

http://www.imf.org/external/pubs/ft/weo/2016 /update/01/

Ref web 4. https://www.zollverein.de/

Ref web 5. http://www.gasometer.de/en/the-gasometer/region.

Ref web 6. http://www.erih.net/welcome.html.

Ref web 7 . http://www.gasometer.de/en/the-gasometer/industrial-culture.

Ref web 8. http://www.gaswerkaugsburg.de.

Ref web 9.

http://www.gaswerk-augsburg.de/europa.htm

Ref web 10.

https://de.wikipedia.org/wiki/Gasometer_münster

Thomas, Russel. 2014. Gasholder and their tanks. www.academia.edu. 